\title{
Lineamientos para los cursos de ley para las mujeres en embarazo o lactantes del Ejército Nacional: propuesta desde un enfoque diferencial ${ }^{1}$
}

https://doi.org/10.21830/9789585318304.08

\author{
Eliana Lizbeth Aparicio Velandia ${ }^{2}$ \\ Escuela de Aviación del Ejército \\ Eder Julián Barbosa Parra ${ }^{3}$ \\ Cristian Javier Anaya Centeno ${ }^{4}$ \\ Cristian Libardo Barbosa Niño \\ Escuela de Armas Combinadas del Ejército \\ María Antonieta Corcione-Nieto ${ }^{6}$ \\ Escuela Militar de Cadetes "General José María Córdova"
}

\section{Resumen}

El objetivo de este capítulo es analizar los lineamientos que rigen internamente al Ejército Nacional de Colombia respecto de los cursos de ley para la mujer en estado de embarazo o

1 Este capítulo presenta los resultados del proyecto de investigación "Enfoques diferenciales en el Ejército Nacional: una propuesta desde las ciencias militares" del Grupo de Investigación en Ciencias Militares, de la Escuela Militar de Cadetes "General José María Córdova" (ESMIC), categorizado en B por Minciencias y con código de registro COL0082556. Los puntos de vista y los resultados de este artículo pertenecen a los autores y no reflejan necesariamente los de las instituciones participantes.

2 Capitán del Ejército Nacional de Colombia. Especialista en Gestión Tecnológica (Pontificia Universidad Javeriana). Profesional en Ciencias Militares y administradora logística (Escuela Militar de Cadetes “General José María Córdova”).

3 Capitán del Ejército Nacional de Colombia. Especialista en Ciencias Militares para el Planeamiento (Centro de Educación Militar). Profesional en Ciencias Militares (Escuela Militar de Cadetes "General José María Córdova”).

4 Capitán del Ejército Nacional de Colombia. Especialista en Ciencias Militares para el Planeamiento (Centro de Educación Militar). Profesional en Ciencias Militares (Escuela Militar de Cadetes "General José María Córdova").

5 Capitán del Ejército Nacional de Colombia. Especialista en Ciencias Militares para el Planeamiento (Centro de Educación Militar). Profesional en Ciencias Militares (Escuela Militar de Cadetes "General José María Córdova").

$6 \mathrm{PhD}$ en Antropología (Universidad de los Andes). Magíster en Biología Humana (Universidad Autónoma de Barcelona). Líder del Grupo de Investigación en Ciencias Militares de la Escuela Militar de Cadetes “General José María Córdova”. Orcid: https://orcid.org/0000-0002-3509-5519 - Contacto: maria.corcione@ esmic.edu.co 
lactante. A partir de los resultados se plantean sugerencias desde un enfoque diferencial para factores no contemplados en la normativa institucional existente. El estudio se desarrolló mediante una metodología cualitativa no experimental de corte transversal: se llevó a cabo una revisión documental del marco normativo sectorial e institucional sobre la protección de la mujer gestante o lactante en el Ejército Nacional y se hicieron entrevistas semiestructuradas a oficiales que estaban tomando el curso de ley. Los resultados evidencian que, aunque existe un importante avance normativo institucional enfocado en la inclusión de la mujer, aún hay mucho por mejorar. En consecuencia, se proponen unos lineamientos con enfoque diferencial y de equidad de género para los cursos de ascenso en beneficio de las mujeres en estado de embarazo y lactancia.

Palabras clave: curso de ascenso; Ejército Nacional de Colombia; enfoque diferencial; mujer militar gestante o lactante

\section{Introducción}

A lo largo de la historia, los roles de las mujeres en la sociedad han estado marcados por constantes luchas por el reconocimiento de sus derechos, pues la discriminación y las violencias de género — que se presentan desde el ámbito familiar-privado y se extienden a todos los espacios públicos, incluidos el profesional y laboral — han sido uno de los más grandes obstáculos.

A pesar de que en el último siglo la participación de la mujer en el mercado laboral ha marcado un hito importante en cuestiones de igualdad de género, aún no se alcanzan los niveles de participación en condiciones de equidad. Los avances normativos internacionales se han enfocado en desarrollar procesos sostenidos para la eliminación de toda discriminación por género, etnia, condición socioeconómica y orientación sexual; por ejemplo, en el 2010, la Asamblea General de las Naciones Unidas crea ONU-Mujeres, que trabaja mundialmente para que los Objetivos de Desarrollo Sostenible sean una realidad para las mujeres y las niñas, y promueve la participación de ellas en igualdad de condiciones en todos los ámbitos de la vida (ONU Mujeres, 2019). Así mismo, los avances normativos nacionales se han alineado con la normatividad internacional en materia de igualdad de derechos y búsqueda de la equidad, empezando por la Constitución Política de 1991. Aunque el compromiso de los Estados en materia de igualdad de derechos es constante, no dejan de presentarse múltiples retos frente a las condiciones que las mujeres deben enfrentar en distintos campos, incluido el militar.

La integración de las mujeres en todos los ámbitos sociales para el cumplimiento de la igualdad de género implica la transversalización del enfoque o pers- 
pectiva de género, que, a su vez, busca integrar las cuestiones atinentes a este tema en la totalidad de los programas sociales. Así, la perspectiva de género quedó establecida como estrategia global para promover la igualdad en la Plataforma de Acción adoptada en la Cuarta Conferencia Mundial de las Naciones Unidas sobre la Mujer, celebrada en Pekín en 1995 (Organización Internacional del Trabajo, 2020). Por otra parte, en 1997, el Consejo Económico y Social de las Naciones Unidas (Ecosoc) definió el concepto de la transversalización de la perspectiva de género en los siguientes términos:

Transversalizar la perspectiva de género es el proceso de valorar las implicaciones que tiene para los hombres y para las mujeres cualquier acción que se planifique, ya se trate de legislación, políticas o programas, en todas las áreas y en todos los niveles. Es una estrategia para conseguir que las preocupaciones y experiencias de las mujeres, al igual que las de los hombres, sean parte integrante en la elaboración, puesta en marcha, control y evaluación de las políticas y de los programas en todas las esferas políticas, económicas y sociales, de manera que las mujeres y los hombres puedan beneficiarse de ellos igualmente y no se perpetúe la desigualdad. El objetivo final de la integración es conseguir la igualdad de los géneros. (Organización Internacional del Trabajo, 2020)

Adoptando la normatividad internacional, en 2018 se emite en Colombia la "Política pública sectorial de transversalización del enfoque de género para el personal uniformado de la Fuerza Pública”, documento que busca la equidad de género, la igualdad de oportunidades y la cero tolerancia frente a las violencias basadas en género, mediante la eliminación de las brechas de desigualdad, el fortalecimiento de la estructura institucional, y la cualificación y competencia del personal (Ministerio de Defensa, 2018). De esta manera, se incentiva la participación de las mujeres en el ámbito laboral y la compaginación de sus vidas personales y de sus proyectos de vida, evitando, principalmente, que se dé por terminado su contrato laboral en caso de embarazo y reconociendo asimismo una licencia de maternidad remunerada, entre otros derechos (Ramírez et al., 2016).

En el camino de búsqueda de equidad, surgen discusiones y posiciones encontradas respecto al doble rol que asumen muchas mujeres; razón por la cual se busca una conciliación entre la vida laboral y la vida personal o familiar, lo que requiere medidas especiales diferenciales, particularmente, en los casos de embarazo, lactancia y maternidad. Al día de hoy, "muchas mujeres se sienten amenazadas por las repercusiones de tomas de tiempo fuera" ${ }^{7}$ reducir su carga de trabajo o hasta

7 El término "tomas de tiempo fuera" hace referencia a los días o semanas de licencia a los que tiene derecho el trabajador, sustentados en causas como la maternidad. 
licencias de maternidad, especialmente en las profesiones o posiciones altamente competitivas" (Molina, 2019).

En esta incertidumbre por la falta de conciliación entre las esferas privadas y públicas — que se han establecido como opuestas e irreconciliables_, se generan situaciones que evidencian la falta de medidas legales y de compromiso por parte de las organizaciones para disponer de mecanismos que permitan a la mujer cumplir con los diversos proyectos de vida. Esto, por supuesto, no la afecta solo a ella, sino también a su entorno cercano, familia, niños, personas a cargo y amistades, lo cual tiene repercusiones en la productividad y, en última instancia, en el desarrollo del país.

Al igual que en el ámbito civil, la mujer que ingresa a las filas de las Fuerzas Militares se enfrenta a una serie estigmas respecto a su capacidad en el trabajo, el papel que cumple dentro de la institución y su aporte a la sociedad en ámbitos de seguridad y defensa. Aunque se han logrado avances en materia de inclusión e igualdad de género, la incorporación de las mujeres al Ejército Nacional de Colombia sigue generando controversia respecto a la limitación de su participación laboral a asuntos administrativos y no operativos, con el argumento de la falta de capacidad en cuanto a destrezas físicas y de fuerza (Cruz, 2004), además de los periodos de embarazo, lactancia y crianza, que se asumen como una debilidad para el cumplimiento de sus deberes.

La inclusión de mujeres a Fuerzas Armadas es una meta de la política de género y el empoderamiento de ella uno de los objetivos, que aún se encuentran en construcción. Si bien la situación de las mujeres difiere de un país a otro, en América Latina existe un denominador común, que refiere que en ningún país de la región las mujeres tienen los mismos derechos y oportunidades que los hombres, por lo que se necesita cambiar paradigmas de una sociedad patriarcal, donde el estatus a las distintas ocupaciones de hombres y mujeres no se determinen por la división sexual del trabajo, donde se logre un empoderamiento de las mujeres, repensando valores y actitudes que impregnan las culturas y contribuyen a la desigualdad entre géneros y es ahí donde radica la importancia de la educación como herramienta de cambio social, para extinguir la transmisión de los roles y estereotipos de género en la Institución Castrense. (Díaz Palacios, 2018, p. 11)

En aras de avanzar en la superación de las condiciones de inequidad, esta investigación se propone realizar un análisis con enfoque de género de los casos de mujeres militares en estado de embarazo o lactancia a las que se les piden pruebas para la aprobación del curso de ley, teniendo en cuenta las experiencias de las tenientes gestantes del curso Intermedio II-2019. Asimismo, esta investi- 
gación presenta un marco normativo de los derechos de la mujer en el régimen militar de Colombia, con un cuidadoso análisis de los lineamientos internos del Ejército Nacional respecto de los cursos de ley para la mujer en estado de embarazo o lactante, enmarcados en el inciso C del artículo 53 del Decreto 1790 de 2000. Con ello, se busca proponer posibles soluciones para factores no contemplados en la normativa institucional existente desde un enfoque diferencial.

\section{Los derechos de las mujeres embarazadas y lactantes: marco normativo nacional e internacional}

A partir de la lucha por la equidad de géneros e igualdad de derechos, ha surgido una serie de instrumentos normativos internacionales y nacionales, así como elementos jurisprudenciales referidos a la protección de los derechos de la mujer, por la necesidad de utilizar un enfoque diferencial para contemplar condiciones naturales del ciclo de vida, como el embarazo, la lactancia y la maternidad.

Uno de los instrumentos normativos internacionales relacionados con los derechos laborales de la mujer es la "Convención sobre la eliminación de todas las formas de discriminación contra la mujer” (CEDAW, por sus siglas en inglés), firmada en 1979, y ratificada por Colombia a través de la Ley 51 de 1981. Los Estados parte de esta Convención asumen el compromiso de desarrollar medidas legales y políticas públicas orientadas no discriminar la mujer (Organización de las Naciones Unidas, 1979). De manera concreta, con relación al derecho a la educación y al trabajo, en el artículo 10 del CEDAW se dispone la obligación de los Estados para desarrollar medidas orientadas a eliminar la discriminación contra la mujer y asegurar la igualdad de derechos en la esfera educativa. Dentro de tales medidas se estipula:

Las mismas condiciones de orientación en materia de carreras y capacitación profesional, acceso a los estudios y obtención de diplomas en las instituciones de enseñanza de todas las categorías [...]; esta igualdad deberá asegurarse en la enseñanza prescolar, general, técnica, profesional y técnica superior, así como en todos los tipos de capacitación profesional [...] La eliminación de todo concepto estereotipado de los papeles masculino y femenino en todos los niveles y en todas las formas de enseńanza, mediante el estímulo de la educación mixta y de otros tipos de educación que contribuyan a lograr este objetivo y, en particular, mediante la modificación de los libros y programas escolares y la adaptación de los métodos de enseñanza. (Organización de las Naciones Unidas, 1979, art. 10) 
En este mismo sentido, el artículo 11, numeral 2, del CEDAW se refiere a las medidas que deben desarrollar los Estados para eliminar la discriminación contra la mujer en el campo laboral por razones de matrimonio o maternidad, buscando condiciones de igualdad y derechos:

a) Prohibir, bajo pena de sanciones, el despido por motivo de embarazo o licencia de maternidad y la discriminación en los despidos sobre la base del estado civil; b) Implantar la licencia de maternidad con sueldo pagado o con prestaciones sociales comparables sin pérdida del empleo previo, la antigüedad o los beneficios sociales; c) Alentar el suministro de servicios sociales de apoyo necesarios para permitir que los padres combinen las obligaciones para con la familia con las responsabilidades del trabajo y la participación en la vida pública, especialmente mediante el fomento de la creación y desarrollo de una red de servicios destinados al cuidado de los niños; d) Prestar protección especial a la mujer durante el embarazo en los tipos de trabajos que se haya probado puedan resultar perjudiciales para ella. (Organización de las Naciones Unidas, 1979, art. 11, num. 2)

De igual manera, otro referente normativo lo constituye la Cuarta Conferencia Mundial de las Naciones Unidas en Beijing (Naciones Unidas, 1995), en la cual se establece una serie de objetivos estratégicos y medidas orientadas al progreso de las mujeres y la igualdad de género. Dicha conferencia abarca esferas tales como mujer y pobreza, educación y capacitación de la mujer, la mujer y la economía, y mecanismos institucionales para el adelanto de la mujer, entre otros. De manera precisa, en este instrumento se reconoce la relación existente entre la pobreza de la mujer y la falta de oportunidades y autonomía económica (Naciones Unidas, 1995), así como la relación directa entre el desarrollo sostenible, el crecimiento económico y la mejora de condiciones económicas, políticas, sociales, jurídicas y culturales de la mujer.

La discriminación en los sistemas de educación y capacitación, así como en las prácticas de contratación, remuneración, ascenso y movilidad horizontal, las condiciones de trabajo inflexibles [...] siguen restringiendo el empleo, así como las oportunidades económicas y profesionales de otra índole y la movilidad de las mujeres. (Naciones Unidas, 1995, p. 92)

Con lo anterior, se consideró necesaria la adopción de medidas que tengan en cuenta el papel de la mujer en la sociedad y eliminar, en consecuencia, las prácticas de discriminación por parte de los empleadores (Naciones Unidas, 1995). De esta manera, se aprecia que varios referentes internacionales hacen hincapié en la necesidad de trabajar en la eliminación de la discriminación de la mujer en el ámbito laboral, mediante el desarrollo de programas de capacitación y la apertura de las 
mismas oportunidades laborales en cuanto a contratación, salario, ascenso y otros aspectos; ya que el desarrollo económico, social, político y cultural de la mujer contribuye también al de las naciones.

Ahora bien, dentro del marco normativo nacional sobre esta materia se encuentra, en primer lugar, la Constitución Política (1991), que aborda la igualdad de libertades, oportunidades, derechos y la no discriminación (art. 13); la igualdad de derechos en hombres y mujeres sin discriminación alguna, gozando la mujer de asistencia y protección por parte del Estado durante periodos de embarazo y después del parto (art. 43); y la igualdad de oportunidades laborales (art. 53) como base fundamental para el desarrollo de la equidad de género.

Igualmente, está la Ley 51 de 1981, por medio de la cual se ratificó la incorporación de la "Convención sobre la eliminación de todas las formas de discriminación contra la mujer" (CEDAW) al bloque constitucional de Colombia; la Ley 82 de 1993, por medio de la cual se desarrolló el marco normativo que obliga al Estado a apoyar a las mujeres cabezas de familia; la Ley 248 de 1995, por la cual se ratificó la "Convención Interamericana para prevenir, sancionar y erradicar la violencia contra la mujer”, conocida también como Convención de Belém do Pará (firmada el 9 de junio de 1994); la Ley 1257 de 2008, que presenta normas de sensibilización, prevención y sanción de la violencia y discriminación contra la mujer; y finalmente el Documento Conpes 161 del 12 de marzo de 2013, por el cual se presenta la Política Pública Nacional de Equidad de Género.

\section{Inclusión de la mujer en escenarios de lucha: el ámbito militar}

A la par del desarrollo normativo nacional e internacional sobre la igualdad de género, se desarrollaron las transformaciones de lo militar para las mujeres. En un principio, en las instituciones castrenses del mundo no se concebía la participación activa de la mujer en el desarrollo de operaciones militares (Delgadillo León, 2010; Forero Moreno, 2005-2004). El ingreso de la mujer al escalafón militar se dio a partir del Decreto 2127 de 1976, cuando doce mujeres profesionales de distintas áreas se incorporaron al cuerpo administrativo del Ejército Nacional (Ejército Nacional de Colombia, 2013). Dicho decreto puede considerarse un hito en la historia de la Fuerza Pública, por cuanto fue el primer paso de incorporación de mujeres al esquema patriarcal del régimen militar de aquel entonces.

Aunque esto significó un logro para la participación de las mujeres en todos los ámbitos profesionales de la sociedad, su incorporación en la carrera militar más 
allá de las áreas administrativas o logísticas ha sido tema de discusión y oposición por parte de funcionarios gubernamentales, de la misma institución y de la sociedad civil, en la mayoría del mundo occidental. La razón de esta oposición es el papel que se le ha asignado a la mujer dentro del sistema patriarcal, como cuidadora, conciliadora, discreta en todos los ámbitos privados, apta para las labores del hogar y la crianza. A esto se suma el estereotipo tradicional de delicadeza, belleza y superficialidad, opuesto a los estereotipos masculinos de valor, fuerza y guerra (Camacho Zambrano, 2011; Zambrano, 2018). Por tanto, asumir una perspectiva de género en el ámbito militar implica hacer un aporte conceptual y metodológico que evidencia la preponderancia de la posición de dominante versus dominado en la relación entre hombres y mujeres en un contexto militar. El enfoque de género ha revelado la posición inequitativa que enfrentan las mujeres que hacen parte del aparato militar (Cuenca, 2011, p. 58).

De manera particular para el caso colombiano, los hallazgos sobre la historia de la incorporación de la mujer al Ejército Nacional en los archivos de la oficina de consulta psicológica develan el disgusto de los hombres al considerar que ese no era un espacio para las mujeres (Cuenca, 2011). Por otro lado, en estos mismos archivos, la queja de las mujeres se enmarcaba en el reclamo por el trato hostil recibido y porque no se les permitía la participación en la toma de decisiones, ni siquiera en el ámbito administrativo, al igual que la sobrecarga de actividades de oficina y el abuso de poder de hombres con cargo superior sobre ellas (Cuenca, 2011).

Otro de los problemas reportados eran las relaciones maritales conflictivas debido a la estructura rígida que separa lo femenino de lo masculino. Davies (1997) documentó casos de vínculos afectivos entre hombres y mujeres militares en los que se presentaban situaciones de conflicto a raíz, principalmente, de la resistencia del hombre por la condición de la mujer en la institución, lo cual se expresaba en trato hostil contra ella, sobrecarga de labores en el hogar y la necesidad de marcar su posición de dominio como militares y jefes. Asimismo, se documenta la histórica posición subordinada de la mujer militar, naturalizada y sustentada en el poder que el Estado concede a los hombres como directos responsables de la defensa de la patria por su capacidad de combate cuerpo a cuerpo en el campo de batalla (Davies, 1997).

Esta relación se observa para las actuales oficiales de armas, que aunque como oficiales tendrán mando de tropa y podrán aspirar al grado de general de la república, en la práctica está restringida su participación directa en hostilidades (Fernández-Osorio \& Latorre Rojas, 2018). Si se conservan las tendencias a 
mantenerlas alejadas de zonas en conflicto, esto puede significar que a futuro se comprometen sus posibilidades de carrera, pues existen ciertas condiciones para los ascensos que están referidas a los puestos y mandos sostenidos, como haber comandado una unidad fundamental o especial o haber sido segunda al mando en las llamadas unidades técnicas y especiales para poder ascender al grado de capitán. Con ello, se puede estar en presencia de los conocidos techos de cristal ${ }^{\beta}$, por tanto se requieren políticas de personal que vayan más allá de la generación de normas (Donadio et al., 2018) y permitan concretamente el desarrollo profesional y de carrera sin el obstáculo del carácter biopsicosocial del género en el mercado laboral (Jato Seijas, 2007).

En esta misma línea, Scott (1990) hace referencia al denominado juego de poderes que se desarrolla en los diferentes espacios de relación de género. Tanto hombres como mujeres militares se encuentran embebidos en un juego en el que el género masculino toma partido del poder que históricamente le ha otorgado la institución, no solo en el campo de batalla, sino en los diferentes sistemas de relaciones que se desarrollan entre los miembros de la institución militar, lo cual se transporta a su vida íntima y familiar. Las mujeres, que han superado el denominado suelo pegajoso ${ }^{9}$ al separarse del estereotipo de los roles de género femeninos tradicionales (Ramos et al., 2003) y ejercer su carrera profesional en el ámbito militar, quedan relegadas nuevamente en este juego de poder a cumplir con lo

8 Ni la mayor presencia de la mujer en el mercado laboral, ni su mejor preparación profesional, permanencia y deseos de promoción han alterado sustancialmente su papel en los ámbitos laborales (Cuadrado \& Morales, 2007). El concepto de techos de cristal ha sido descrito por sociólogas y economistas de la década de los ochenta para exponer cómo la proporción de mujeres disminuye a medida que se asciende en la jerarquía piramidal laboral. Se denominó así porque no existe una ley que impida a las mujeres avanzar en sus trayectorias profesionales, por tanto se trata de barrera invisible pero difícil de traspasar. Al preguntarse por qué mujeres con un alto grado de educación y experiencia se encontraban en una proporción minoritaria en altos cargos directivos, se encontró que las largas jornadas laborales propias de la función directiva, además de una escasa sensibilidad de las empresas sobre la conciliación de la vida familiar y laboral en algún momento de sus carreras, hacen que las mujeres se encuentren con esa superficie superior invisible llamada techo de cristal (Burin, 2008). Asimismo, se dice que las mujeres son menos competitivas y ambiciosas que los varones, por lo que no negocian aumentos salariales. Otro de los motivos del techo de cristal es la segregación en el mercado laboral, donde los hombres y las mujeres tienden a trabajar en diferentes sectores y tareas que se valoran de forma desigual (Ortiz Jiménez, 2014). También incide en el techo de cristal la concepción social sobre la maternidad y el papel que las mujeres han de desempeñar ante ella, pues la maternidad y las responsabilidades familiares constituyen el aspecto que más dificulta el acceso de las mujeres a los cargos directivos (Díez Gutiérrez et al., 2009).

9 Las mujeres en espacios laborales o profesionales se enfrentan no solo a un techo de cristal que les impide acceder a los puestos superiores de la escala, sino a un suelo pegajoso, que les impide acceder a los primeros niveles de la carrera académica (Torres González \& Pau, 2011). Este suelo pegajoso parte de la distribución desproporcionada de mujeres y varones por sectores laborales específicos — segregación horizontal—, que se evidencia en la clasificación de lo masculino y femenino como criterio para ejercer determinadas labores. La segregación de género se convierte en discriminatoria en la medida en que las actividades laborales femeninas van acompañadas de sueldos más bajos, mayor índice de desempleo, menor valoración social y mayor inestabilidad (Barberá et al., 2001). 
tradicional dentro de la institución. Por tanto, este juego de poderes se convierte en una dinámica constante que inicia con este suelo pegajoso y transcurre con la imposición de los techos de cristal.

Las tareas domésticas, la maternidad, el cuidado de hijos y adultos mayores impiden a las mujeres desprenderse de esa superficie pegajosa y, cuando lo hacen, la mayoría choca con el "techo de cristal" que es esa barrera invisible que representa los prejuicios sobre la capacidad de las mujeres para desempeñarse de manera profesional. (Torres González \& Pau, 2011, pp. 35-59)

A pesar de lo anterior, a lo largo del tiempo y de las transformaciones que han sufrido las Fuerzas Militares, se han presentado avances significativos en cuanto a la vinculación femenina a sus filas bajo condiciones de igualdad de oportunidades, gracias a procesos de trasformación social, cultural y política que han dado campo a la generación de políticas de género en el ámbito castrense (Camacho Zambrano \& Contreras Ortiz, 2012). Uno de los más importantes fue la creación, en 2013, de un observatorio militar para la equidad entre hombres y mujeres en la Escuela Militar de Cadetes "General José María Córdova” (Fernández-Osorio \& Latorre Rojas, 2018), que al día de hoy sigue realizando actividades de investigación y monitoreo. En cuanto a la participación de la mujer en el Ejército Nacional se sabe que "actualmente, el personal militar femenino constituye el 3,5\% de los oficiales y suboficiales de la Institución, siendo el $87 \%$ del Cuerpo Administrativo y se mantiene la incorporación de Oficiales de las Armas en un 17,3\% en promedio desde el año $2009^{10}$ (Ministerio de Defensa Nacional, 2017, p. 23).

Dentro de las estrategias con enfoque de género y acciones afirmativas ${ }^{11}$ llevadas a cabo por el Ejército Nacional, se encuentra la creación de la Oficina de Género en el año 2016, encargada de formular lineamientos para fortalecer el proceso de integración de la mujer en las escuelas de formación, para insistir en la igualdad de oportunidades y derechos ("Crean en el Ejército una oficina de equidad de género para las mujeres militares”, 2016). Estas estrategias han impulsado la ejecución de

10 En enero del 2009 ingresó a la ESMIC la primera promoción mixta con 62 cadetes, de las cuales se graduaron 48 en diciembre de 2011, quienes podrán acceder al grado de general desde distintas armas. En el 2019 estas mujeres — quienes participan en este estudio — se encontraban realizando el curso de ley para ascenso de teniente a capitán en la Escuela de Armas Combinadas del Ejército.

11 En el documento "Política pública sectorial de transversalización del enfoque de género para el personal uniformado de la Fuerza Pública”, del Ministerio de Defensa Nacional, se definen las acciones afirmativas como aquellas orientadas a la reducción de las brechas de desigualdad y barreras discriminatorias que afectan a grupos minoritarios o vulnerables de la sociedad, con lo cual se busca dar cumplimiento al derecho a la igualdad, consagrado en el artículo 13 de la Constitución Política de Colombia 
múltiples trabajos en la materia, como son los procesos de capacitación, formación y entrenamiento con enfoque de género; el apoyo en el desarrollo de políticas de transformación; la participación en la campaña de la ONU y la Alta Consejería para la Equidad de la Mujer, denominada He for She (ONU-Mujeres 2017), en donde se promueve el reconocimiento y los derechos de las mujeres; así mismo, desde la Dirección de Sanidad, se desarrollan acciones para la atención y prevención de violencias basadas en género (Ministerio de Defensa Nacional, 2018).

Estos esfuerzos han permitido el reconocimiento del pie de fuerza femenino dentro del Ejército Nacional. Además, discriminar entre hombres y mujeres permite una comprensión holística de la presencia de mujer en sus filas y el desarrollo de su carrera, lo cual ha evidenciado la relación desigual entre géneros en los grados de oficiales y suboficiales (tabla 1). Para el caso del grado de capitán, las mujeres representan el 6,9\% de los oficiales, proporción que disminuye en el grado de coronel, con una representación del 4,1\% de mujeres coroneles; sin ninguna representación femenina en los grados de mayor general y general (tabla 1). Esta situación se repite entre las suboficiales, por ejemplo, el 1,94\% de personal con grado de sargento segundo son mujeres, mientras que el 5,6\% del personal de sargento primero son mujeres (tabla 1).

Tabla 1. Personal del Ejército Nacional discriminado entre hombres y mujeres (mayo 2017)

\begin{tabular}{llcc}
\hline Escalafón & \multicolumn{1}{c}{ Grado } & Mujeres & Hombres \\
\hline \multirow{6}{*}{ Oficiales } & General & 0 & 4 \\
& Mayor general & 0 & 24 \\
& Brigadier general & 2 & 41 \\
& Coronel & 21 & 483 \\
& Teniente coronel & 87 & 705 \\
& Cayor & 37 & 1.794 \\
& Tenitán & 186 & 2.583 \\
& Subtente & 138 & 1.851 \\
& Subtotal & 310 & 1.460 \\
& & 781 & 8.945 \\
\hline
\end{tabular}

Continúa tabla... 


\begin{tabular}{llcc}
\hline Escalafón & \multicolumn{1}{c}{ Grado } & Mujeres & Hombres \\
\hline & $\begin{array}{l}\text { Sargento mayor } \\
\text { de Comando } \\
\text { Conjunto }\end{array}$ & 0 & 0 \\
& $\begin{array}{l}\text { Sargento mayor } \\
\text { de Comando }\end{array}$ & 0 & 99 \\
& Sargento mayor & 2 & 300 \\
& Sargento primero & 198 & 3.325 \\
Suboficiales & Sargento & 3 & 3.488 \\
& viceprimero & 171 & 8.628 \\
& Sargento segundo & 194 & 5.967 \\
& Cabo primero & 23 & 5.543 \\
& Cabo segundo & 94 & 4.927 \\
& Cabo tercero & 685 & 32.277 \\
\hline Subtotal & & \\
\hline
\end{tabular}

Fuente: Ministerio de Defensa Nacional, 2017, p. 33

Con lo anterior, se observa que aunque los porcentajes de participación aún son bajos, las Fuerzas Militares cada día abren más sus puertas a la inclusión femenina en sus filas, de cara a las necesidades que se presentan en cargos de toma de decisiones y aquellos en los que se resaltan sus competencias y capacidades en beneficio de los resultados que demandan los distintos cuerpos y especialidades.

Ante este panorama, se han desarrollado diferentes investigaciones nacionales y foráneas, en especial, en cuanto a los derechos de la mujer gestante y lactante en el ámbito civil (por ejemplo, Acosta, 2009; Almanza Iglesias et al., 2018; Caamaño Rojo, 2009) y castrense (De Angelis et al., 2018; Gómez, 2013; Horzella, 2018). Estos estudios y otros más cuestionan, resaltan y proponen estrategias de participación de las mujeres en distintos escenarios laborales y profesionales. Por su parte, Molina (2019) señala que la decisión de ser madre representa para muchas mujeres consecuencias laborales, puesto que las organizaciones no se han preocupado por establecer mecanismos que permitan conciliar el rol familiar y laboral de la mujer. Aunque las licencias de maternidad en algunos casos favorecen la permanencia de las mujeres en la fuerza laboral, debido a que es más rápido y fácil que vuelvan al trabajo; en otros casos, las mujeres se enfrentan a la decisión de escoger entre su carrera profesional y su familia, después de terminada la licencia (Molinos, 2012). 
Asimismo, Lopera y Estrada (2015) refieren el registro de varios fallos de la Corte Constitucional a favor de la mujer gracias al marco legal nacional en cuanto sus derechos, con lo cual se busca dar cumplimiento a las normativas internacionales que a las que se ha adherido el bloque constitucional del país. No obstante, en Colombia se precisa que las instituciones académicas y la sociedad en general ejerzan control permanente sobre la aplicación de las normas, leyes y políticas en esta materia, con el fin de obtener avances significativos en materia de igualdad y equidad de género.

Por otra parte, Cerquera (2018) muestra de qué manera la Corte Constitucional ha violado el principio mínimo de estabilidad laboral. Dentro de los hallazgos reportados, expone la doble connotación de la estabilidad laboral, considerada como derecho fundamental y como un principio mínimo fundamental en el trabajo. Además, reconoce que las reformas laborales flexibles que se han ido instaurando en el país han conllevado a una disminución de la protección estatal de la estabilidad laboral. No obstante, se evidencia que la Corte Constitucional ejerce un mayor grado de protección frente a la mujer en estado de gravidez.

Por su parte, Ramírez et al. (2016) analizan el efecto de la legislación protectora de la maternidad en la vida laboral de las mujeres. Encuentra que la extensión de la licencia de maternidad de 12 a 14 semanas dispuesta a través de la Ley 1468 de 2011 generó un incremento en la probabilidad de inactividad para las mujeres en edades más fértiles (18 a 30 años), lo que aumenta los niveles de informalidad y autoempleo. A su vez, esto se traduce en efectos laborales ya que "en algunos casos, las protecciones jurídicas imponen costos a quienes intentan beneficiar" (p. 286). Así las cosas, se precisa que este tipo de regulaciones se complemente con otras disposiciones para prevenir la exclusión del grupo objetivo por parte de los empleadores, ya que estos prefieren contratar mujeres en edades no reproductivas u hombres, en su defecto, para evitar correr con los altos gastos que representan las licencias de maternidad.

De igual manera, Ortiz (2018) estudia la efectividad de los instrumentos normativos de la Organización de las Naciones Unidas y la Organización Internacional del Trabajo en materia de protección a la maternidad en Colombia. Los resultados evidencian que los diferentes instrumentos sobre el tema se orientan a una garantía de estabilidad económica para la mujer gestante y en periodo de prueba y en el acceso a prestaciones asistenciales para que el embarazo sea llevado a buen término.

De este modo, es evidente que las investigaciones aquí presentadas centran su atención en el principio de estabilidad laboral, la discriminación y la protección de 
la mujer gestante o no en el país; sin embargo, el tema no ha sido abordado desde el ámbito militar. Además, para el caso particular de los cursos de ley de ascenso, los enfoques diferenciales no se han tenido en cuenta dentro del Ejército Nacional.

\section{Los cursos de ley}

Dentro de las Fuerzas Militares de Colombia, el Centro de Educación Militar (CEMIL) es el órgano encargado de la educación y capacitación de los militares en el Ejército Nacional por medio de las escuelas de formación militar adscritas, donde efectúa los respectivos cursos de ley para el ascenso de oficiales y suboficiales.

El curso de ley es un curso obligatorio, reglamentado por el Decreto 1790 de 2000 (artículos 53 y 54) y la Ley 1104 de 2006, y constituye uno de los requisitos mínimos para el ascenso de los suboficiales y oficiales. En este curso se recibe entrenamiento y capacitación para el desarrollo de nuevas funciones y el ejercicio del mando, responsabilidades a las que se verá enfrentado el militar en el grado siguiente. Cada uno de los cursos de ascenso no podrá ser reemplazado por trabajos o pruebas de conocimientos y deberá tener un componente presencial obligatorio. De otra parte, el programa de estos cursos deberá contener los temas de liderazgo y ética militar o policial correspondientes a su nuevo grado, los cuales serán cursados de manera presencial (Ministerio de Defensa Nacional, 2008).

El curso de ley contempla los siguientes requisitos mínimos de ascenso, contenidos en el Manual de procedimientos académicos del Centro de Educación Militar (CEMIL, 2017):

a. Tener el tiempo mínimo de servicio efectivo establecido para cada grado en el presente Decreto.

b. Capacidad profesional, acreditada con las evaluaciones anuales reglamentarias.

c. Adelantar y aprobar los cursos de ascenso reglamentarios.

d. Acreditar aptitud psicofísica de acuerdo con el reglamento vigente.

e. Acreditar los tiempos mínimos de mando de tropa, embarco o vuelo, para los grados de Subteniente, Teniente, Capitán y sus equivalentes en la Armada Nacional, como se estipula en el presente Decreto.

f. Concepto favorable de la Junta Asesora del Ministerio de Defensa.

g. Tener la clasificación para ascenso de acuerdo con el Reglamento de Evaluación y Clasificación.

Para su aprobación, se establece que el alumno debe:

1. Aprobar todos los saberes con nota igual o superior al $60 \%$ equivalente a 3.0 
2. Aprobar los exámenes de habilitación si se presentara el caso.

3. Aprobar la especialización de las armas.

4. Asistir como mínimo al $90 \%$ de las horas programadas en todas las fases y saberes complementarios. La inasistencia debe ser justificada.

5. Para la aprobación del curso, el alumno deberá obtener un promedio no inferior al $60 \%$ en el saber de Fortalecimiento Físico al finalizar el curso, equivalente a una nota de 3.0, pero no tiene derecho al distintivo de la Escuela. (CEMIL, 2017)

Por último, antes de dar inicio al curso, los estudiantes deben presentar una prueba física. Si el resultado obtenido en esta prueba es inferior al $70 \%$, se dispone que: “[...] se les consignará en su respectivo Folio de Vida, en el indicador cultura física, describiendo su falta de compromiso y responsabilidad para iniciar el curso de capacitación" (CEMIL, 2017).

\section{Método}

El desarrollo de esta investigación se enmarcó en la exploración de datos, que se llevó a cabo una sola vez, para analizar e identificar aquellos factores que dificultan el desarrollo del curso de ley por parte de uniformadas del Ejército Nacional en estado de embarazo o lactancia. La recolección de información se hizo a partir de fuentes primarias, como las entrevistas semiestructuradas realizadas a mujeres oficiales o suboficiales del Ejército Nacional, estudiantes del curso de ley intermedio II-2019, en condición de estado de embarazo o lactancia o que sean madres de familia.

Además, el examen de información se realizó a través de un análisis de contenido mediante una revisión documental orientada a reconocer el marco normativo sectorial e institucional en materia de protección laboral de la mujer gestante o lactante. Se buscó hacer una descripción y análisis de dicho marco, reconociendo las protecciones y posibilidades de ascenso que se brindan en el Ejército Nacional a las mujeres en estado de embarazo o lactancia. También se buscó analizar los factores y circunstancias descritas por las entrevistadas respecto a las oportunidades u obstáculos que han percibido en su proceso académico con relación a su papel como madres. Con base en dicho análisis, se propuso una serie de lineamientos complementarios a los ya existentes en la normativa institucional del Ejército Nacional encaminados al tratamiento de las circunstancias o factores que podrían obstaculizar el proceso formativo y de ascenso de las uniformadas. 


\section{Dificultades de las mujeres en estado de embarazo en el curso de ley para ascenso}

Los resultados de las entrevistas realizadas a mujeres en estado de embarazo que se encontraban haciendo el curso intermedio para el ascenso de teniente a capitán en el 2019 — curso que dura seis meses, para la promoción las primeras mujeres de arma de combate- evidenciaron los siguientes aspectos de las dificultades y circunstancias que deben sortear en dicho proceso formativo y de ascenso.

Las entrevistadas manifestaron que sus comandantes no contaban con las herramientas políticas y administrativas —en el sentido de normativas- que les permitieran comprender su estado de gravidez; por tanto, las mujeres buscaron mecanismos alternos que les permitieran evidenciar sus capacidades más allá de la destreza física, y exigieron medios alternos como los trabajos escritos para lograr calificaciones de prueba física con puntajes mayores al $70 \%$.

Por otra parte, las mujeres entrevistadas manifestaron que no consideraban que su estado de embarazo fuera una limitante para el desarrollo del curso de ley, pues no lo veían como un problema que implicara el aplazamiento o desistimiento de sus aspiraciones personales y profesionales; por el contrario, expresaron que las limitantes eran circunstanciales y se derivaban de la ausencia de lineamientos y políticas que establecieran variantes para el curso y las pruebas destinados a las mujeres en estado de embarazo y lactancia.

Al momento de indagar sobre los medios alternos de evaluación implementados en el curso intermedio para suplir los requerimientos del área física, las participantes manifestaron no tener claridad al respecto, lo que se convertía en especial preocupación al considerar sus limitaciones para ciertas pruebas de esfuerzo y horarios que no se compaginan con los horarios de lactancia y asistencia materna.

También manifestaron las entrevistadas total acuerdo con la implementación de herramientas para llevar a cabo el curso de ley de manera no presencial para casos de permisos de lactancia y maternidad, así como en casos de embarazos considerados de alto riesgo. Del mismo modo, se declara un mayor sentimiento de seguridad si en su periodo de gestación pueden alternar el curso no solo en la Escuela de Armas Combinadas del Ejército (ESACE), sino de forma virtual o no presencial, teniendo en cuenta el estado en el cual se encuentran.

Por último, las entrevistadas expresaron la necesidad del diseño e implementación de directrices con enfoque diferencial, que les permita a los comandantes tener una hoja de ruta frente al proceso que deben llevar las mujeres en estado de gravidez y lactancia, sin que sus circunstancias amenacen el desarrollo del curso y, en consecuencia, la posibilidad de ascenso. 


\section{Análisis del marco normativo sectorial sobre protección de la mujer gestante o lactante}

$\mathrm{Al}$ ser un Estado constitucional, Colombia sienta sus bases en principios de justicia e igualdad para todos sus ciudadanos. Para ello se consagran en sus ordenamientos superiores las normas que ofrecen la igualdad formal. Sin embargo, estos mandatos son insuficientes cuando históricamente existen grupos que han soportado discriminaciones por razones de credo religioso, político, de género u orientación sexual. Por esa razón, en los mismos ordenamientos se han incluido preceptos para promover el logro de la igualdad material y se ha impuesto al Estado la obligación de proponer mecanismos para hacer efectiva dicha garantía (Pabón Mantilla \& Aguirre Román, 2009). Ya que la maternidad ha sido uno de los factores que generan discriminación y desigualdad de género en materia laboral, se han establecido acuerdos y tratados nacionales e internacionales que buscan eliminar las brechas de género.

En el desarrollo de esta promoción de mecanismos, para el marco normativo sectorial en materia de protección de la maternidad, se resalta, para el interés de este estudio, la Política Integral de Derechos Humanos (DD. HH.) y Derecho Internacional Humanitario (DIH) del Ministerio de Defensa; la Directiva Permanente N. ${ }^{\circ}$ 30, referente a la "Equidad de género para las mujeres en las Fuerzas Militares, garantías y respeto de sus derechos"; la Directiva Permanente -20151110000277MDN-CGFM-JEMC-SEMCFJI23.1-, la cual presenta los "Lineamientos Estratégicos para las Fuerzas Militares en equidad de género, enfoque diferencial y prevención de la violencia sexual basada en género" (Ministerio de Defensa Nacional Comando \& General de las Fuerzas Militares, 2015); y el Manual del procedimientos académicos del Centro de Educación Militar, en el que se estipulan las diferentes disposiciones académicas respecto de los cursos militares y cursos de ley (CEMIL, 2017).

Como punto de partida en este análisis, es preciso resaltar que el derecho a la igualdad no necesariamente se refiere al trato que recibe el hombre y la mujer por parte de la sociedad o el Estado, sino que el entendimiento de este concepto se extiende a la igualdad de oportunidades. De acuerdo con esto último, la mujer, en ciertas etapas o ciclos de la vida como el embarazo, la lactancia y la maternidad merece un enfoque diferencial, es decir, debe primar la equidad en los escenarios laborales para evitar los suelos pegajosos y los techos de cristal. Sobre este factor, en la Directiva Permanente N. 30 se expone que 
se justifica entonces que las Fuerzas Militares deban trabajar para lograr la Equidad de Género para las mujeres, dando un tratamiento diferenciado que compense las desigualdades de partida entre hombres y mujeres y permita alcanzar una verdadera igualdad en términos de derechos, beneficios, obligaciones y oportunidades a las mujeres. (Ministerio de Defensa Nacional \& Comando General de las Fuerzas Militares, 2015, marzo 10)

De esta manera, se reconoce la necesidad de que dentro de las instituciones de la Fuerzas Militares del país se diseñen medidas orientadas a igualar las oportunidades laborales y al reconocimiento de los espacios femeninos como relevantes, teniendo presente el enfoque diferencial basado en un tratamiento particular orientado a la compensación de las desigualdades entre géneros.

En la Directiva Permanente N.o 030 del 10 de marzo de 2015 del Comando General de las Fuerzas Militares también se reconocen los derechos de la mujer contemplados en la ley y en los convenios internacionales ratificados por el Estado colombiano. Sobre tales derechos, en lo concerniente al tema laboral, se mencionan los siguientes:

m. El derecho de la mujer a ser libre de toda forma de discriminación.

n. El derecho de la mujer a ser valorada y educada libre de patrones estereotipados de comportamiento y prácticas sociales y culturales basadas en conceptos de inferioridad o subordinación.

o. El derecho al trabajo como derecho inalienable de todo ser humano.

p. El derecho a las mismas oportunidades de empleo, el derecho al ascenso, a la estabilidad en el empleo y a todas las prestaciones y otras condiciones de servicio, y el derecho al acceso a la formación profesional y al adiestramiento, incluido el aprendizaje, la formación profesional y el adiestramiento periódico.

q. El derecho a igual remuneración.

r. El derecho a la seguridad social.

s. El derecho a prestaciones familiares.

t. El derecho a la protección de la salud y a la seguridad en las condiciones de trabajo, incluso la salvaguardia de la función de reproducción.

Con esto, se resalta la necesidad de precisar lineamientos específicos para evitar factores circunstanciales que puedan condicionar la efectividad de tales derechos al interior de la institución militar, especialmente en el marco del desarrollo del curso de ley para el ascenso laboral de mujeres uniformadas en estado de embarazo o lactancia, que resulten en aspectos discriminatorios que no permitan el pleno desarrollo personal y laboral.

Para el cumplimiento de tales derechos, en la Directiva N. ${ }^{\circ} 30$ se dispone una serie de misiones a distintos órganos de las Fuerzas Militares, como se resume en la tabla 2. 
Tabla 2. Misiones particulares para la promoción de la equidad de género

\begin{tabular}{|c|c|}
\hline Órgano & Misiones \\
\hline \multirow[t]{3}{*}{$\begin{array}{l}\text { Jefatura de Educación } \\
\text { y Doctrina Conjunta }\end{array}$} & $\begin{array}{l}\text { Aplicación de contenidos normativos referentes al enfoque de } \\
\text { género. }\end{array}$ \\
\hline & $\begin{array}{l}\text { Incorporación de conceptos y normas sobre equidad de género a } \\
\text { los procesos de formación y capacitación, promoviendo la equidad } \\
\text { de género, sensibilizando sobre los derechos de la mujer desde una } \\
\text { perspectiva histórica, de modo que se promueva la reflexión, se } \\
\text { reduzcan las resistencias, se promueva el cambio hacia una menor } \\
\text { tolerancia de las violencias basadas en género. }\end{array}$ \\
\hline & Capacitación a formadores en temas de equidad de género. \\
\hline \multirow{2}{*}{$\begin{array}{l}\text { Oficina de } \\
\text { Comunicaciones } \\
\text { Estratégicas del } \\
\text { Comando General } \\
\text { de las Fuerzas Militares }\end{array}$} & $\begin{array}{l}\text { Diseño y ejecución de estrategias de comunicación y movili- } \\
\text { zación institucional para sensibilizar y formar en equidad de } \\
\text { género, buscando mayor posicionamiento de la mujer dentro de } \\
\text { las FF. MM. como constructoras de paz. }\end{array}$ \\
\hline & $\begin{array}{l}\text { Liderar mensajes en medios de comunicación exaltando el trabajo } \\
\text { y el rol de la mujer dentro de las FF. MM. }\end{array}$ \\
\hline Comandos de Fuerza & $\begin{array}{l}\text { Fortalecer los sistemas de seguimiento y monitoreo de quejas } \\
\text { reportadas por mujeres militares como alerta temprana para la } \\
\text { prevención de violaciones a sus derechos. } \\
\text { Desarrollo de capacitaciones y actualizaciones extracurriculares } \\
\text { sobre equidad de género, dirigidas a todo el personal, con el fin } \\
\text { de promover la protección de las mujeres. } \\
\text { Implementar un punto de atención de quejas, denuncias y } \\
\text { asesoría para mujeres militares a través de las Jefaturas de Familia. }\end{array}$ \\
\hline
\end{tabular}

Fuente: Elaboración propia a partir del Ministerio de Defensa Nacional y Comando General de las Fuerzas Militares (2015, marzo 10)

Por otro lado, la Directiva Permanente N. o 20151110000277, referente a los "Lineamientos Estratégicos para las Fuerzas Militares en equidad de género, enfoque diferencial y prevención de violencia basada en género”, aborda las medidas que debe desarrollar el Ejército Nacional con el objetivo de facilitar la inclusión de la política de género en el ámbito laboral (Ministerio de Defensa Nacional \& Comando General de las Fuerzas Militares, 2015, octubre 1. ${ }^{\circ}$ ). Para ello, parte de los principios de igualdad y hace explícito que las mujeres no son el complemento de los hombres, sino parte integral del equipo. También introduce algunas modificaciones en otros asuntos no menos importantes, como la dimensión familiar de los miembros (hombres y mujeres) de las Fuerzas Armadas (Galvis, 2016).

Otros instrumentos normativos sectoriales son: la Directiva Permanente N. ${ }^{\circ}$ 00849 de septiembre de 2016, la cual aborda los "Lineamientos generales de preven- 
ción de la violencia basada en género y definición de los mecanismos de sensibilización, capacitación y denuncia al interior del Ejército Nacional" (Ministerio de Defensa Nacional \& Comando Nacional de las Fuerzas Militares, 2016, septiembre 7); la Politica en derechos sexuales y reproductivos, equidad y violencia basada en género, salud sexual y reproductiva, con énfasis en VIH (Ministerio de Defensa Nacional, 2010); y los Lineamientos de la política sectorial para la transversalización del enfoque de género (TEG) (Ministerio de Defensa Nacional, 2017).

Este último instrumento institucional presenta una serie de principios, objetivos, líneas de acción y acciones estratégicas orientadas a "impulsar la inclusión y la transversalización del enfoque de género y diferencial al interior de la Fuerza Pública”. En relación con el tema de estudio que se abarca en este capítulo, una de las líneas de acción de este instrumento es la "protección y garantía de los derechos humanos con enfoque de género y diferencial”, y una de sus acciones estratégicas es

promover acciones afirmativas, tendientes a solucionar, de manera efectiva, las necesidades y problemáticas relacionadas con la proyección de carrera en cada uno de los cuerpos y especialidades; ellos, con el fin de potencializar el desarrollo militar, profesional, personal y familiar de personas que integran la Fuerza Pública, desde los enfoques de género, derechos humanos y diferencial. (Ministerio de Defensa Nacional, 2017, p. 53)

Del mismo modo, se plantea la institucionalización del enfoque de género en el sector defensa, lo que genera en su interior el Área de Género del Ministerio de Defensa, una de cuyas funciones es

elaborar lineamientos sectoriales para el mejoramiento de las condiciones de acceso, permanencia y progreso en la carrera militar, destinadas a erradicar obstáculos y promover acciones tendientes a garantizar la igualdad real de oportunidades para hombres y mujeres. (Ministerio de Defensa Nacional, 2017, p. 58)

Todo esto desde la transversalización del enfoque de género, que busca materializar la normativa existente por medio de la implementación de los siguientes ejes: equidad de género, inclusión, no discriminación, interculturalidad, participación, autonomía, empoderamiento, bienestar y sostenibilidad (Ministerio de Defensa Nacional, 2017).

Por otro lado, en la Directiva Permanente 1020 de 22 de noviembre de 2016 (Ejército Nacional, Departamento de Personal, 2016), se definieron los "Lineamientos en materia de equidad de género, enfoque diferencial y prevención de violencia basada en género para el Ejército Nacional”. Así, quedaron establecidas distintas actividades que deben ser desarrolladas por distintos órganos institucio- 
nales para la inclusión de la política de equidad de género. Como justificación para la definición de dichos lineamientos,

se reconoce la existencia de relaciones de jerarquía desiguales entre hombres y mujeres, expresadas en algunos eventos particulares, en opresión y discriminación, de forma desventajosa hacia la mujer; lo anterior justificado en la reciente participación que en el ejercicio del mando militar, ha tenido la mujer desde la fundación Ejército Nacional, brecha que se pretende romper con el presente documento. (Ejército Nacional, Departamento de Personal, 2016, p. 5)

Con lo citado en la Directiva 1020, se reconoce la necesidad de maximizar los esfuerzos institucionales en materia de equidad de género, enfoque diferencial y violencia, con base en el género dentro del Ejército Nacional. En este marco de ideas, se definió una serie de misiones particulares de diferentes dependencias y unidades orgánicas del Ejército Nacional. En relación con el tema de interés de este capítulo se resaltan las siguientes misiones de responsabilidad del Comando de Educación y Doctrina:

Desarrollar de forma progresiva, integrada y armónica, la inclusión de los lineamientos de equidad de género, enfoque diferencial y prevención de la violencia basada en género, en los programas académicos para las Escuelas de Formación y Capacitación [...]. Incorporar en la reglamentación militar temas que regulen las actividades del personal, relacionados con situaciones de maternidad, paternidad, lactancia y embarazo de las estudiantes de formación, garantizando en todos los casos los derechos constitucionales. (Ejército Nacional, Departamento de Personal, 2016, p. 11)

Como se puede apreciar, estas misiones buscan facilitar los procesos de formación y el acceso a programas académicos para mujeres lactantes o en estado de embarazo, así como educar a los compañeros militares en el respeto y la inclusión. Esto resulta sumamente importante, pues el enfoque de equidad de género favorece el mejoramiento de las condiciones de vida de las personas. En efecto, una mejora en la calidad de vida de los militares tendrá un efecto directo en sus familias. Con esto, se entiende que dentro de la Fuerza Pública se diseñan acciones que permiten potencializar y dar solución a problemas de proyección de carrera, como ocurre en el caso de mujeres embarazadas o lactantes que encuentran obstáculos en sus ascensos a razón de su estado.

El diseño de tales acciones es el resultado de la aplicación de un enfoque diferencial de género con el propósito de reducir la desigualdad e inequidad contra las mujeres como consecuencia de las asimetrías de relaciones de poder. Para el 
caso de la maternidad esto es de especial interés, debido a que el rol tradicional que ha sido asignado a la mujeres, haciéndolas responsables de mantener la casa y la familia, es considerado por la Organización Internacional del Trabajo (OIT) como uno de los factores que determinan y proporcionan condiciones de trabajo desiguales para las mujeres. Esto es así no solo con relación a los hombres, sino con relación a las mujeres mismas, debido a que aquellas que han asumido la maternidad tienen disminuidas las posibilidades de mejores condiciones laborales y de ascenso al entrar en conflicto ambas esferas (familiares y laborales) (Pabón Mantilla \& Aguirre Román, 2009).

Finalmente, en el Manual de procedimientos académicos del Centro de Educación Militar están contenidas las disposiciones académicas para los cursos militares y cursos de ley. Al analizar en dicho documento aquellos factores que pueden dificultar a las uniformadas en estado de embarazo o lactancia el desarrollo y culminación de dicho curso se encontró, especialmente, las disposiciones referentes a las pruebas físicas. La primera de estas pruebas es aplicada al inicio de dicho curso, y su calificación debe ser superior al $70 \%$, de lo contrario, el estudiante recibe una anotación en su Folio de Vida en donde se señala su falta de compromiso y responsabilidad con la capacitación.

Por otro lado, dentro de las causales de pérdida de curso se encuentran las siguientes:

1. Obtener en el saber de Ejercicio de simulación de guerra una nota inferior a 3.0, teniendo en cuenta que este saber no es habilitable.

2. Obtener un promedio inferior al $60 \%$ en el saber de fortalecimiento físico al finalizar el curso, equivalente a una nota de 3.0. (CEMIL, 2017, p. 54)

Ahora bien, dentro del contenido de dicho manual no se establecen medidas especiales para el caso de mujeres en estado de embarazo o lactancia que estén desarrollando el curso de ley, lo cual requiere especial atención considerando que su estado puede impedirles el desarrollo de ciertos esfuerzos físicos, que pueden amenazar su propia integridad y la vida del bebé. Sumado a esto, la limitación física de las mujeres en embarazo no necesariamente supone una "falta de compromiso y responsabilidad" (CEMIL, 2017, p. 53) para con su proceso formativo, sino que simplemente debe es una condición circunstancial que merece un trato especial y diferenciado. Con esto, las disposiciones sobre la realización de pruebas físicas establecen la presentación de incapacidad física por parte del área de Sanidad Militar y la opción de que quienes tengan incapacidad médica no asistan a los cursos presenciales y puedan realizarlos de manera virtual. 


\section{Propuesta de lineamientos para la protección de los derechos de las mujeres embarazadas y lactantes desde un enfoque diferencial}

Las características de la profesión militar (disponibilidad, movilidad forzosa, despliegues internacionales, maniobras, guardias, etc.) hacen especialmente importante que se revisen los lineamientos para la protección de los derechos de las mujeres embarazadas y lactantes, en especial, para aquellas que están próximas a o se encuentran realizando el curso de ley.

Si bien se ha podido identificar que a nivel institucional el Ejército Nacional cuenta con instrumentos normativos enfocados en el reconocimiento de los derechos de la mujer como la igualdad, la equidad, la no discriminación, el trabajo, las mismas oportunidades de empleo y el desarrollo de una política con enfoque diferencial, se ha apreciado que para el caso de las mujeres embarazadas o en lactancia que realizan el curso de ley para el ascenso no se han especificado lineamientos claros y diferenciados en su práctica. Igualmente, en el Manual de procedimientos académicos no se especifican requisitos o medidas diferenciadas dirigidos a mujeres en embarazo o lactancia ni su inclusión, a pesar de que los trabajos de actividad física no son funcionales para su estado.

Con lo anterior, se ha encontrado la necesidad de aportar sugerencias para la definición de lineamientos anexos que permitan orientar a los comandantes encargados qué hacer respecto a estos casos, además de disponer de métodos alternos de evaluación y del diseño e implementación de directrices que permitan facilitar el proceso formativo de las uniformadas.

Así, en relación con los instrumentos normativos institucionales reconocidos dentro del Ejército Nacional sobre este tema y considerando la necesidad de que la Escuela de Armas Combinadas del Ejército Nacional (ESACE) ejerza iniciativas ejemplificantes en cuanto a la creación de directrices orientadas a impulsar la participación activa de la mujer en sus diferentes ámbitos académicos, se proponen a continuación algunos lineamientos con enfoque diferencial para su aplicación frente a casos de mujeres uniformadas en estado de embarazo o lactancia que realizan el curso de ley para ascenso:

a. Que los comandantes encargados de la dirección y ejecución de cursos de ley para ascenso cuenten con capacitación sobre los derechos de las mujeres y trato diferencial que precisan aquellas en estado de embarazo, especialmente, en cuanto a capacidad y esfuerzos físicos. 
b. Que el Comando de Personal, con especialistas realice una revisión de las pruebas físicas que se llevan a cabo en el curso de ley, identificando cuáles de ellas pueden poner en riesgo la gestación de la mujer, razón por la cual se considerarán inconvenientes.

c. Diseñar pruebas alternas que reemplacen las pruebas físicas inconvenientes para las mujeres en estado de gestación, considerando, entre ellas, la participación en proyectos de investigación con impacto institucional.

d. Crear una nueva área para las mujeres en estado de embarazo que supla el área de entrenamiento físico, de manera que sea provechoso para su estado de embarazo. Entre esto podría considerarse un plan de acondicionamiento para el pleno desarrollo del embarazo o curso profiláctico, curso de gimnasia preparto y charlas enfocadas en el deporte o en actividades físicas que beneficien el estado de gestación.

e. En cumplimiento de las misiones definidas en la Directiva N.o 30, se recomienda a la Jefatura de Educación y Doctrina Conjunta adelantar, desde el curso de ley, procesos de formación y capacitación sobre equidad de género con el propósito de disminuir las resistencias y ampliar la tolerancia y el respeto para con la mujer.

f. Definir en el Manual de procedimientos académicos de la ESACE de forma clara los procedimientos, requisitos, derechos, deberes y demás normas relacionadas con el enfoque diferencial para los casos de mujeres en estado de embarazo o lactancia que desarrollen el curso de ley.

g. Establecer estándares especiales de calificación para que sean aplicados a las mujeres uniformadas en estado de embarazo que realicen el curso de ley, de acuerdo con sus capacidades.

h. Desarrollar una plataforma virtual para casos especiales como lo son embarazos de alto riesgo, considerando las restricciones médicas, de forma que sea posible capacitar al personal femenino que presente esta condición.

i. Implementar simuladores para que el personal que por motivos de estado embarazo o lactancia no pueda asistir a las campañas, pueda efectuar de manera más real los ejercicios tácticos. Esto con el fin de que sus conocimientos y capacidades sean nivelados con relación al personal que sí puede asistir a dichas campañas.

j. Analizar la posibilidad de incluir un observatorio de la mujer en la ESACE, con el fin de que sirva como veedor de todas las escuelas del CEMIL y desarrolle trabajos de análisis de los requerimientos de la mujer para plasmar de manera idónea funciones, responsabilidades y parámetros de las uniformadas en estado de embarazo o lactancia en los diferentes cursos de capacitación.

k. Implementar sistemas de videoconferencia para que las mujeres en embarazo o lactancia puedan presentar sus exposiciones, exámenes o atender a sus clases en casos de cumplimiento de controles, citas médicas y demás ausencias justificadas concernientes a su estado. 
1. Establecer el uso de uniformes para mujeres en estado de embarazo, teniendo en cuenta el reglamento de uniformes, insignias y distinciones RGE-4-20.1.

m. Otra medida alineada con la Directiva N.o 030 es que, desde los Comandos de Fuerza, se instalen oficinas encargadas de realizar trabajos de seguimiento y monitoreo sobre el respeto y reconocimiento de los derechos de las mujeres. De esta manera, se busca generar alertas tempranas para la prevención frente a casos de algún tipo de violencia o al no reconocimiento de uno de estos casos. Los trabajos de seguimiento no solo deben realizarse sobre las quejas reportadas por las mujeres militares, sino que se precisa que se acompañen por trabajos de investigación en campo respecto del ambiente laboral que día a día viven las mujeres militares. Para ello se requiere enfocar la atención en aquellas que se encuentran en estado de embarazo y, por ende, presentan cierto tipo de vulnerabilidad y limitaciones en su carga de esfuerzos. Estos trabajos de seguimiento deben tener como propósito el diseño de medidas necesarias para el manejo de situaciones que puedan atentar contra el bienestar y la salud de la futura madre y su hijo.

n. El desarrollo de capacitaciones y actualizaciones extracurriculares sobre equidad de género que se realicen desde los Comandos de Fuerza, de acuerdo con lo estipulado en la Directiva N. ${ }^{\circ} 30$, deben abordar los derechos y la protección de la mujer en estado de embarazo, su derecho al trabajo y el trato diferencial que le corresponde.

o. Que las Jefaturas de Familia encargadas de la atención de quejas y denuncias de mujeres militares, de acuerdo con lo dispuesto en la Directiva N. ${ }^{\circ} 30$, desarrollen un trabajo conjunto con otros órganos institucionales en donde se emprendan planes y proyectos orientados al manejo de las problemáticas reportadas, de forma que se haga seguimiento de estas situaciones hasta su solución final.

p. De acuerdo con los Lineamientos de la Política Sectorial para la Transversalización del Enfoque de Género, se recomienda que el área de Género del Ministerio de Defensa trabaje en la revisión de aquellos factores que pueden estar afectando a las mujeres embarazadas en su progreso y permanencia en la carrera militar, y que se diseñen medidas orientadas a garantizar oportunidades equitativas en materia de ascenso.

q. En cumplimiento de la Directiva 1020, el Comando de Educación y Doctrina debe incorporar en la reglamentación militar disposiciones en materia de maternidad, paternidad, lactancia y embarazo para los estudiantes en formación. Así, entre dichas disposiciones se precisa la necesidad de reconocer el derecho al ascenso de las mujeres, de manera que la etapa de embarazo no sea un condicionante o limitante para la efectividad de su cumplimiento. De esta manera, se precisa identificar dentro del diseño de los cursos de ley qué factores pueden estar vulnerando dicho derecho en mujeres embarazadas, con el fin de desarrollar medidas encaminadas a su corrección.

r. Merece también atención el desarrollo de medidas que permita a las mujeres en embarazo gozar de un seguimiento no solo sobre su aspecto físico y la evolu- 
ción de su gestación, sino también sobre su salud psicológica, para identificar y atender aquellos factores que la puedan perjudicar emocionalmente, entre ellos, la falta de consideración sobre su estado por parte de sus superiores o formadores.

s. Se recomienda que los órganos competentes dentro del Ejército Nacional trabajen en la articulación de programas para concientizar a los uniformados sobre el sexismo y la equidad de género, desarrollando acciones tendientes a: (i) la sensibilización y formación en temas de igualdad de género, para la no discriminación por condición de género o ciclo vital; (ii) la eliminación de imágenes con estereotipos sexistas en materiales institucionales tales como publicaciones, documentos y propaganda, entre otros; (iii) garantizar un sistema de comunicación interno que elimine el lenguaje sexista; (iv) diseño de campañas permanentes a favor de la política diferencial de género; y (v) el diseño de talleres en materia de género y mujer gestante y lactante.

t. Elaboración de informes periódicos, por parte de los órganos encargados, sobre los trabajos y avances logrados en materia de género, de modo que se permita un seguimiento y monitoreo de las recomendaciones que emanan de los diferentes instrumentos normativos institucionales y de los mismos informes.

u. Hacer una revisión y actualización periódica de las directrices y lineamientos establecidos sobre la mujer, a través de conferencias, foros y charlas en las que se discutan sus necesidades.

v. Es indispensable que en la ESACE se cuente con instructoras femeninas, para apoyar en los casos especiales a las mujeres en estado de embarazo o lactancia.

w. En cumplimiento del artículo 238 del Código Sustantivo de Trabajo, se hace necesario que en las instalaciones donde se desarrollan los cursos militares se disponga de un espacio óptimo y digno para que las mujeres lactantes puedan extraer la leche materna, conservarla en condiciones adecuadas y transportarla de manera segura.

\section{Conclusiones}

Ante la existencia de una posible situación discriminatoria generalizada en el mercado laboral, es necesario incorporar la perspectiva de género desde un enfoque diferencial en el análisis de las organizaciones.

Para el caso de esta investigación se identificó que el Ejército Nacional, como organización, presenta una notable evolución institucional que ha permitido la inclusión de mujeres en áreas de trabajo distintas a la administrativa. Estos nuevos espacios ocupados por ellas han generado nuevos retos para la implementación de la igualdad de oportunidades y el establecimiento pleno de la equidad entre los miembros del Ejército Nacional. 
No obstante, aún se precisa el desarrollo de directrices y lineamientos con enfoque diferencial de género orientado a las mujeres en estado de embarazo o lactancia que planean o adelantan cursos de ley para su ascenso. De esta forma se superarían los obstáculos del suelo pegajoso y el techo de cristal para las mujeres en estado de embarazo o lactancia que se encuentran realizando el curso de ley, en especial, porque sus comandantes y superiores no cuentan con directrices claras respecto al manejo que deben seguir sobre estos casos.

La institución cuenta con diferentes instrumentos normativos internos que reconocen las necesidades del desarrollo de medidas y acciones en materia de equidad de género; el tratamiento diferenciado compensatorio de desigualdades en materia de derechos, beneficios, obligaciones y oportunidades; la promoción de acciones afirmativas para las necesidades de proyección de carrera; y la elaboración de lineamientos para la mejora de condiciones de acceso, permanencia y progreso en la carrera militar de las mujeres. A pesar de ello, en la práctica se precisa ahondar en dichos aspectos de manera más coordinada y eficiente, además de trabajar profundamente en la sensibilización de compañeros, comandantes y mandos superiores.

En consecuencia, la propuesta de lineamientos para implementar en los cursos de ley aquí presentada pretende — desde un enfoque diferencial — tener en cuenta los ciclos de vida y decisiones de las mujeres sobre la maternidad, sin que estos sean un impedimento para el desarrollo de su carrera. La propuesta guarda relación de coherencia con los distintos instrumentos normativos institucionales sobre la materia, por lo cual se busca su complementación y continuidad.

\section{Referencias}

Acosta, P. (2007). La protección de los derechos de las mujeres en la Constitución colombiana. Revista Derecho del Estado, 20, 49-60.

Almanza Iglesias, M., Carpintero Mercado, K., \& Mercado Villa, L. K. (2018). Estabilidad laboral de la mujer trabajadora en estado de embarazo. Ergaomnes, 10(1), 129-155. https://doi. org/10.22519/22157379.1216

Barberá, E., Ramos, A., Sarrió, M., \& Candela, C. (2002). Más allá del techo de cristal. Diversidad de género. Revista del Ministerio de Trabajo y Asuntos Sociales, 40, 55-68.

Burin, M. (2008). Las "fronteras de cristal” en la carrera laboral de las mujeres. Género, subjetividad y globalización. Anuario de psicología, 39(1), 75-86.

Caamaño Rojo, E. (2009). Los efectos de la protección a la maternidad para la concreción de la igualdad de trato entre hombres y mujeres en el trabajo. Revista de Derecho de la Pontificia Universidad Católica de Valparaíso, 33, 175-214. 
Camacho Zambrano, C. (2011). Políticas de equidad de género en las Fuerzas Armadas. Impactos en la cultura institucional militar; el caso de la incorporación de cadetes femeninas en la ESMIC. Revista Cientifica General José María Córdova, 9(9), 69-94. https://doi.org/10.21830/19006586.246

Camacho Zambrano, C., \& Contreras Ortiz, I. (2012). Observatorio de equidad de género para el proceso de incorporación y seguimiento del personal estudiantil femenino en la ESMIC. Revista Cientifica General José María Córdova, 10(10), 187-216. https://doi. org/10.21830/19006586.234

CEMIL. (2017). Manual de procedimientos académicos. Centro de Educación Militar (CEMIL). Fuerzas Militares de Colombia.

Cerquera, S. (2018). El principio de estabilidad laboral en Colombia: la tensión entre los derechos laborales vs. las politicas neoliberales de flexibilización. Universidad Nacional de Colombia.

Crean en el Ejército una oficina de equidad de género para las mujeres militares. (2016). RCN Radio. https://www.rcnradio.com/colombia/crean-ejercito-una-oficina-equidad-genero-las-mujeres-militares

Cruz, J. (2004). Reflexiones sobre la presencia de la mujer en los ejércitos desde una perspectiva histórico-jurídica. Impreandes.

Cuadrado, I., \& Morales, F. (2007). Algunas claves sobre el techo de cristal en las organizaciones. Revista de Psicología del Trabajo y de las Organizaciones, 23(2), 183-202.

Cuenca, Y. (2011). La participación de algunas mujeres en el Ejército Nacional de Colombia. La Manzana de la Discordia, 6(2), 57-63. https://doi.org/10.25100/lamanzanadeladiscordia. v6i2.1498

Davies, Y. (1997). Gender, the military and the nation. Sage.

De Angelis, K., Smith, D., \& Segal, M. (2018). Military families: A comparative perspective. En G. Caforio, \& M. Nuciari (Eds.), Handbook of the sociology of the military (pp. 341-357). Springer. https://doi.org/10.1007/978-3-319-71602-2

Delgadillo León, C. (2010). La evolución de la mujer en las filas del Ejército. Ejército Nacional en Guardia por Colombia.

Díaz Palacios, D. (2018). Rediseño del syllabus de la asignatura de Derechos Humanos incluyendo la perspectiva de género, para los institutos de perfeccionamiento de Fuerzas Armadas en el Ecuador. Revista de Ciencias de Seguridad y Defensa, 3(4), 11-36.

Díez Gutiérrez, E., Terrón Bañuelos, E., \& Anguita Martínez, R. (2009). Percepción de las mujeres sobre el techo de cristal en educación. Revista Interuniversitaria de Formación de Profesorado, 64, $27-40$.

Donadio, M., Klepak, H., Kussrow, S., \& Rial, J. (2018). Misiones militares y posconflicto: una mirada regional sobre Colombia. Resdal. https://www.resdal.org/assets/diagnostico_colombia_ resdal-esp-2018.pdf

Ejército Nacional de Colombia. (2013, agosto 29). La fuerza también tiene heroinas: el papel de la mujer en el Ejército colombiano. https://www.ejercito.mil.co/index.php?idcategoria=349399

Ejército Nacional, Departamento de Personal. (2016). Directiva Permanente N.o 1020. Asunto: Lineamientos en materia de equidad de género, enfoque diferencial y prevención de violencia basada en género para el Ejército Nacional. Bogotá, D.C.

Fernández-Osorio, A., \& Latorre Rojas, E. (Eds.). (2018). La construcción del rol de la mujer militar. Escuela Militar de Cadetes "General José María Córdova”. 
Forero Moreno, I. (2004-2005). La mujer en la historia militar. Academia Colombiana de Historia Militar, Boletín N. ${ }^{\circ}$ 3, 264-275.

Galvis, C. (2016). La mujer, soporte clave en el cumplimiento de la misión. Memorias del VII seminario internacional en derechos humanos y DICA 2016. Estrategias de la sociedad civil y las Fuerzas Militares para la consolidación y construcción de la paz en Colombia. Escuela Superior de Guerra. https://esdeguelibros.edu.co/index.php/editorial/catalog/view/12/9/20-1

Gómez, M. (2013). La familia en las Fuerzas Armadas españolas. Ministerio de Defensa.

Horzella, B. (2018). Normas de protección a la maternidad en las FF. AA. y en Fuerzas de Orden y Seguridad Pública. https://obtienearchivo.bcn.cl/obtienearchivo?id=repositorio/10221/26824/2/Informe_ BCN_Normas_de_Proteccion_a_la_Maternidad_en_las_FFAA_y_de_Orden_y_Seguridad_ Final.pdf

Jato Seijas, E. (2007). El desarrollo de la carrera profesional de las mujeres: Particularidades y obstáculos. Revista Portuguesa de Pedagogía, 41(3), p. 151-171.

Lopera, M., \& Estrada, L. (2015). Derechos laborales y de la seguridad social para las mujeres en Colombia en cumplimiento de la Ley 1257 de 2008. Revista de Derecho, 44, 269-296. https:// www.redalyc.org/pdf/851/85141031012.pdf

Ministerio de Defensa Nacional \& Comando General de las Fuerzas Militares. (2015, marzo 10). Directiva Permanente N. ${ }^{0}$ 030. Asunto: Equidad de Género para las mujeres de las Fuerzas Militares, garantías y respeto de sus derechos. No Radicado: 20151280265271 / MND-CGFMJEDHDIH-DHADI 25-11. Bogotá, D.C.

Ministerio de Defensa Nacional \& Comando General de las Fuerzas Militares. (2015, octubre 1. ${ }^{\circ}$ ). Directiva Permanente N. ${ }^{\circ}$ 20151110000277. Asunto: Lineamientos estratégicos para las Fuerzas Militares en equidad de género, enfoque diferencial y protección de violencia basada en género. Bogotá, D.C.

Ministerio de Defensa Nacional \& Comando Nacional de las Fuerzas Militares. (2016, septiembre 7). Directiva Permanente N. ${ }^{\circ} 00849$. Asunto: Lineamientos generales de prevención de la violencia basada en género y definición de los mecanismos de sensibilización, capacitación y denuncia al interior del Ejército Nacional. Bogotá, D.C.

Ministerio de Defensa Nacional. (14 de septiembre de 2000). Decreto 1790 de 2000; por el cual se modifica el Decreto que regula las normas de carrera personal de oficiales y suboficiales de las Fuerzas Militares. Diario Oficial N. ${ }^{\circ} 44.161$. Bogotá, D.C.

Ministerio de Defensa Nacional. (2008). PEFA, Proyecto Educativo de las Fuerzas Militares.

Ministerio de Defensa Nacional. (2010, agosto). Política en derechos sexuales y reproductivos, equidad y violencia basada en género, salud sexual y reproductiva, con énfasis en VIH. Unidad de Comunicaciones UNFPA.

Ministerio de Defensa Nacional. (2017). Politica pública sectorial de transversalización del enfoque de género para el personal uniformado de la Fuerza Pública 2018-2027. Bogotá, D.C. Mindefensa.

Ministerio de Defensa Nacional. (2018). Política pública sectorial de transversalización del enfoque de género para el personal uniformado de la Fuerza Pública.

Molina, M. (2019). El rol de la mujer como madre trabajadora y sus repercusiones en el ámbito laboral y familiar [Trabajo de grado, Universidad del Azuay]. Repositorio Institucional. http://dspace. uazuay.edu.ec/handle/datos/9164

Molinos, C. (2012). La ley de protección de la maternidad como incentivo de participación laboral femenina: el caso colombiano. Coyuntura económica, 42(1), 93-116. 
Naciones Unidas. (1995, septiembre). Cuarta Conferencia Mundial Sobre la Mujer. A/CONF.177/20. http://www.equidadmujer.gov.co/ejes/Documents/NormativaNacional/Cuarta $\% 20$ Conferencia\%20Mundial\%20sobre\%20la\%20Mujer\%20en\%20Beijing\%20de\%201995.pdf

ONU-Mujeres. (2017). Ejército Nacional se suma a la campaña He For She de ONU Mujeres. https:// colombia.unwomen.org/es/noticias-y-eventos/articulos/2017/03/heforshe-ejercito

ONU-Mujeres. (2019). Acerca de ONU mujeres. Trabajo y prioridades. https://www.unwomen.org/es/ about-us/about-un-women

Organización de las Naciones Unidas. (1979). Convención sobre la eliminación de todas las formas de discriminación contra la mujer (CEDAW). https://www2.unwomen.org/-/media/field\%20 office $\% 20$ mexico/documentos/publicaciones/2011/convenci\%C3\%B3n\%20pdf.pdf?la=es

Organización Internacional del Trabajo. (2020). Instrumentos para la igualdad de género. http://www. ilo.org/public/spanish/bureau/gender/newsite2002/about/defin.htm

Ortiz Jiménez, C. (2014). Techos de cristal y suelos pegajosos en la vida laboral de la mujer [Tesis de grado, Universidad del País Vasco]. https://addi.ehu.es/bitstream/handle/10810/14677/ TFG-Cristina\%20Ortiz.pdf? sequence=3\&isAllowed $=y$

Ortiz, C. (2018). La OIT y la ONU frente a la garantía de la estabilidad laboral reforzada de la mujer en estado de embarazo en Colombia [Tesis de pregrado]. Universidad de Cartagena.

Pabón Mantilla, A. M., \& Aguirre Román, J. O. (2009). La protección jurisprudencial a la maternidad en Colombia. Revista Diálogos de Saberes, 31, 263-282.

Ramírez, N., Tribín, A., \& Vargas, C. (2016). Maternidad y mercado laboral: el impacto de la legislación. En L. E. Arango, F. Castellani, \& E. Lora, Desempleo femenino en Colombia (pp. 297-289). Banco de la República.

Ramos, A., Barberá, E., \& Sarrió, M. (2003). Mujeres directivas, espacio de poder y relaciones de género. Anuario de Psicología, 34(2), 267-278.

Scott, J. (1990). El género, una categoría útil para el análisis histórico. En J. Amelang, \& M. Nash (Eds.), Historia y género. Las mujeres en la Europa Moderna y Contemporánea. Alfons el Magnanim.

Torres González, O., \& Pau, B. (2011). “Techo de cristal” y “suelo pegajoso”. La situación de la mujer en los sistemas alemán y español de ciencia y tecnología. Revista Iberoamericana de Ciencia, Tecnología y Sociedad-CTS, 6(18), 1-24.

Zambrano, C. (2018). Caleidoscopio. Estudio sobre feminidades y perspectivas de género en el contexto militar colombiano. Escuela Militar de Cadetes "General José María Córdova”. https://doi. org/10.21830/9789585200838 